\title{
Ranking of Two Multi Criteria Decision Making Cases with Evidential Reasoning under Uncertainty
}

Farzaneh Ahmadzadeh*

Post-Doctoral, Department of Innovation, Design and Engineering, University of Mälardalen, 631 05, Eskilstuna, Sweden

A R T I C L E I N F O

Article history:

Received: 21 April, 2017

Accepted: 15 June, 2017

Online: 15 July, 2017

Keywords:

Evidential reasoning

Uncertainty

Decision making

Prioritization

\begin{abstract}
A B S T R A C T
Many decision problems have more than one objective that need to be dealt with simultaneously. Moreover, because of the qualitative nature of the most of real world problem it is an inevitable activity and very important to interpret and present the uncertain information for making effective decision. The Evidential Reasoning (ER) approach which is one of the latest development within multi criteria decision making (MCDM) seems to be the best fit to synthesize both qualitative and quantitative data under uncertainty. To support this claim, two case studies were tested to illustrate the application of ER for prioritization and ranking of decision alternative to support decision process even with uncertain information. The overall goal of the first case study is to identify and prioritize factors that can be considered maintenance-related waste within the automotive manufacturing industry. The result after applying ER shows "inadequate resources" and "weather /indoor climate," respectively, are the highest and lowest average scores for creating maintenance-related waste. This prioritization methodology can be used as a tool to create awareness for managers seeking to reduce or eliminate maintenance-related waste. The aim of the second case study is to look at the possibility of having a new approach for sustainable design. So through a literature review six design strategies were taken into consideration in order to develop a new approach based on all advantages (sustainable factors) of the six approaches. For ranking and finding out about the most important factors the evidential reasoning (ER) approach is used. Based on ER all the important factors, apart from the one collected from interviews are a part of eco-design. So it means among all strategies eco-design is the most dominant strategy in term of environment. However two of the important factors are not found in any strategy but in interviews. These factors can be used as the building blocks for a new approach. The importance of having a better structured decision process is essential for the success of any organization, so it can be applied widely in most of real world problem dealing with making effective decision.
\end{abstract}

\section{Introduction}

It has become more and more difficult to see the world around us in a uni-dimensional way and to use only a single criterion when judging what we see [1]. The decision making process for any organization may be key factor for its success. Decision maker's wishes to evaluate the performance of the alternative with different criteria simultaneously. In many situations these objectives/ criteria may be conflicting. These objectives are associated with the possible consequences (or outcomes) that results from choosing an alternative [2]. The branch of decision analysis which deals with this kind of problem is called multicriteria decision making (MCDM). Many MCDM methods have been developed, such as multiple attribute utility theory (MAUT)

* Corresponding Author: Farzaneh Ahmadzadeh, Mälardalens högskola, 63105 Eskilstuna | Email: Farzaneh.ahmadzadeh@mdh.se

www.astesj.com

https://dx.doi.org/10.25046/aj0203134 and analytical hierarchy process (AHP) [3, 4]. Most of these methods are suitable for solving small scale MCDM problems without uncertainty. In uncertain situations, the Fuzzy MultiCriteria Decision Making (FMCDM) approach provides an ideal option; it has been tested by a number of researchers to rank alternatives in different situations [5]. However, the fuzzy approach is used only when uncertainty is predominant. In other words, when a particular parameter is quantifiable with fair degree of accuracy, or there are a missing or incomplete data this approach need not be used. Most real-life decisions use a mixture of qualitative and quantitative attributes with varying degrees of uncertainties, increasing the need for the development of scientific methods and tools that are rational, reliable, repeatable, and transparent. Since, it is essential to properly represent and use uncertain information for making effective decision, it is 
compulsory to use the multi-level evaluation framework for assessing different type of uncertainty inherent in data like missing data, incomplete data which is one of the many research limitation when it comes to qualitative data. Therefore in this paper an evidential reasoning (ER) approach has been introduced to address this problem. Two case studies is examined to emphasize the effectiveness of this approach. The rest of the paper is organized as follows. Section 2 briefly outlines the Evidential Reasoning (ER) approach. Section 3 explains the first case study for prioritization of maintenance related waste. Section 4 provides the second case study when it has been applied for developing a sustainable product design, while Section 5 offers a conclusion.

\section{Evidential Reasoning Approach}

The Evidential Reasoning (ER) advocates a general, multi-level evaluation process for dealing with MCDM problems. The process can model various types of qualitative and quantitative uncertainties and is developed on the basis of Dempster-Shafer evidence theory [6] and evaluation analysis model and decision theory. In ER, A complex general property which is usually difficult to assess directly is broken down and operationalized by using well-defined, measurable concepts that together constitute the general property. The result of such a breakdown is a multiple attribute framework taking the shape of a tree (hierarchy) structure, with assessable basic attributes at the lowest level. The assessment of these basic attributes can be aggregated to an assessment of the upper level of the tree. The Dempster-Shafer mathematics are designed to aggregate the uncertainties in the basic attributes to a total uncertainty of the total assessment. Steps for the overall assessment of the complex general property are suggested in $[6,7]$ and summarized in [8] are as following:

\subsection{Definition and representation of a multiple attribute decision problem}

Define a set of $\mathrm{L}$ basic attributes include all the factors influencing the assessment of the upper level attribute as follows:

$E=\{\varepsilon 1, \varepsilon 2, \ldots, \varepsilon L\}$

Now estimate the relative weights of the attributes where $\omega_{i}$ is the relative weight for basic attribute $\varepsilon_{i}$ and is normalized so that $\sum \omega_{i=1}$ and $0 \leq \omega_{i} \leq 1$. Moreover define $N$ distinctive evaluation grades $H_{n}, n=1, \ldots, N$ as a complete set of standards to assess each option on all attributes.

For example:

$H=\left\{H_{1}=\right.$ worst,$H_{2}=$ poor,..,$H_{N-1}=$ Good, $H_{N}=$ Excellent $\}$

For each attribute $\varepsilon_{i}$ and evaluation grade $H_{n}$ a degree of belief $\beta_{n}$ is assigned. The degree of belief denotes the source's level of confidence when assessing the level of fulfillment of a certain property.

\subsection{Basic probability assignments for each basic attribute}

Let $m_{n, i}$ be a basic probability mass, representing the degree to which the $i^{\text {th }}$ basic attribute $\varepsilon_{i}$ supports a hypothesis that the general attribute is assessed to the $n^{\text {th }}$ evaluation grade $H_{n}$. Then, $m_{n, i}$ is calculated as follows:

$$
m_{\mathrm{n}, \mathrm{i}}=\omega_{\mathrm{i}} \beta_{\mathrm{n}, 1}
$$

Let $m_{\mathrm{H}, \mathrm{i}}$ be the remaining probability mass unassigned to each basic attribute $\varepsilon_{i,}$, so $m_{H, i}$ is calculated as follows :

$$
\begin{gathered}
m_{H, i}=1-\sum_{n=1}^{N} m_{n, i}=1-\omega i \sum_{n=1}^{N} \beta_{n, i} \\
\text { Decompose } m_{H, i} \text { into } \bar{m}_{\mathrm{H}, \mathrm{i}} \text { and } \widetilde{m}_{\mathrm{H}, \mathrm{i}} \text { as follows: } \\
\bar{m}_{\mathrm{H}, \mathrm{i}}=1-\omega_{\mathrm{i}} \text { and } \widetilde{m}_{\mathrm{H}, \mathrm{i}=} \omega_{\mathrm{i}}\left(1-\sum_{n=1}^{N} \beta_{n, i}\right) \\
m_{\mathrm{H}, \mathrm{i}}=\bar{m}_{\mathrm{H}, \mathrm{i}}+\widetilde{m}_{\mathrm{H}, \mathrm{i}}
\end{gathered}
$$

\subsection{Combined probability assignments for a general attribute}

The assessments of the basic attributes constituting the general property are aggregated to form a single assessment of the general property. The probability masses assigned to the various assessment grades, as well as the probability mass left unassigned, are denoted by $m_{\mathrm{n}, \mathrm{I}(\mathrm{L})}, \bar{m}_{\mathrm{H}, \mathrm{I}(\mathrm{L})}, \widetilde{m}_{\mathrm{H}, \mathrm{I}(\mathrm{L})}$ and $m_{\mathrm{H}, \mathrm{I}(\mathrm{L})}$. Let $I(1)=1$. This gives us $m_{n, I(1)}=m_{n, I}(n=1, \ldots, N), \bar{m}_{H, I(1)}=\bar{m}_{H, 1}, \tilde{m}_{H, I(1)=} \tilde{m}_{H, 1}$ and $m_{H, I(I)}=m_{H, I}$. The combined probability masses can be generated by aggregating all the basic probability assignments using the following recursive ER algorithms:

$\left\{H_{n}\right\}$ :

$$
\begin{gathered}
m_{\mathrm{n}, \mathrm{I}(\mathrm{i}+1)}=\mathrm{K}_{\mathrm{I}(\mathrm{i}+1)}\left[m_{\mathrm{n}, \mathrm{I}(\mathrm{i})} \times m_{\mathrm{n}, \mathrm{i}+1}+m_{\mathrm{H}, \mathrm{I}(\mathrm{i})} \times m_{\mathrm{n}, \mathrm{i}+1}+m_{\mathrm{n}, \mathrm{I}(\mathrm{i})} \times m_{\mathrm{H}, \mathrm{i}+1}\right] \\
n=\{1,2, \ldots, N\}
\end{gathered}
$$

In equation (5), we continue to let $i=1$. The term $m_{n, 1}, m_{n, 2}$ measures the degree of attributes $\varepsilon_{1}$ and $\varepsilon_{2}$ supporting the general attribute $y$ to be assessed to $H n$, the term $m_{n, 1}, m_{H, 2}$ measures the degree of only $\varepsilon_{l}$ supporting $y$ to be assessed to $H_{n}$, and the term $m_{H, 1}, m_{n, 2}$ measures the degree of only $\varepsilon_{2}$ supporting $y$ to be assessed to $H_{n}$.

$\{H\}$ :

$$
\begin{gathered}
m_{\mathrm{H}, \mathrm{I}(\mathrm{i})}=\bar{m}_{\mathrm{H}, \mathrm{I}(\mathrm{i})}+\tilde{m}_{\mathrm{H}, \mathrm{I}(\mathrm{i})} \\
\tilde{m}_{\mathrm{H}, \mathrm{I}(\mathrm{i}+1)}=\mathrm{K}_{\mathrm{I}(\mathrm{i}+1)}\left[\tilde{m}_{\mathrm{H}, \mathrm{I}(\mathrm{i})} \times \tilde{m}_{\mathrm{H}, \mathrm{i}+1}+\bar{m}_{\mathrm{H}, \mathrm{I}(\mathrm{i})} \times \widetilde{m}_{\mathrm{H}, \mathrm{i}+1}+\tilde{m}_{\mathrm{H}, \mathrm{I}(\mathrm{i})} \times \bar{m}_{\mathrm{H}, \mathrm{i}+1}\right] \\
\mathrm{H,I( \textrm {i } + 1 )}=\mathrm{K}_{\mathrm{I}(\mathrm{i}+1)}\left[\bar{m}_{\mathrm{H}, \mathrm{I}(\mathrm{i})} \times \bar{m}_{\mathrm{H}, \mathrm{i}+1}\right] \\
\mathrm{K}_{\mathrm{I}(\mathrm{i}+1)}=\left[1-\sum_{t=1}^{N} \sum_{\substack{j=1 \\
j \neq t}}^{N} m_{t, I(i)} \cdot m_{j, i+1}\right]^{-1} i=\{1,2, \ldots, L-1\}
\end{gathered}
$$

In equation (7), the term $\widetilde{m}_{\mathrm{H}, 1}, \widetilde{m}_{\mathrm{H}, 2}$ measures the degree to which $y$ cannot be assessed to any individual grades due to the incomplete assessments for both $\varepsilon_{1}$ and $\varepsilon_{2}$. The term $\bar{m}_{\mathrm{H}, 1}, \widetilde{m}_{\mathrm{H}, 2}$ measures the degree to which $y$ cannot be assessed due to incomplete assessments for $\varepsilon_{2}$ only. The term $\tilde{m}_{\mathrm{H}, 1}, \bar{m}_{\mathrm{H}, 2}$ measures the degree to which $y$ cannot be assessed due to incomplete assessments for $\varepsilon_{1}$ only. The term $\bar{m}_{\mathrm{H}, 1}, \bar{m}_{\mathrm{H}, 2}$ in equation (8) measures the degree to which $y$ has not yet been assessed to individual grades due to the relative importance of $\varepsilon_{1}$ and $\varepsilon_{2}$ after $\varepsilon_{1}$ and $\varepsilon_{2}$ have been aggregated. $\mathrm{K}_{\mathrm{I}(2)}$ as calculated by equation (9) is used to normalize $\mathrm{m}_{\mathrm{n}, \mathrm{I}(2)}$ and $\mathrm{m}_{\mathrm{H}, \mathrm{I}(2)}$ so that :

$$
\sum_{n=1}^{N} m_{n, I(2)}+m_{H, I(2)}=1
$$

\subsection{Calculation of the combined degrees of belief for a general property}

Calculating the combined degrees of belief for a higher level property. Let $\beta_{n}$ denote the combined degree of belief that the higher level property assessed to the grade $H_{n}$, generated by combining the assessments for all the associated basic attributes $\varepsilon_{i} . \beta_{n}$ is then calculated by:

$$
\begin{gathered}
\left\{H_{n}\right\}: \beta n=\frac{m_{n, I(L)}}{1-\bar{m}_{H, I(L)}} n=\{1,2, \ldots, N\} \\
\{H\}: \beta n=\frac{\widetilde{m}_{H, I(L)}}{1-\bar{m}_{H, I(L)}}
\end{gathered}
$$


Steps 1-4 can now be employed for the other sub-trees, to obtain combined degree of belief for the higher level of the hierarchy model.

\subsection{Using linear utility function}

In this step, the utilities of the respective assessment grades $H_{l \ldots \mathrm{n}}$ are estimated via utility functions $\left(u\left(H_{n}\right)\right)$. This estimation can be accomplished for instance by means of a range of methods and techniques that can be utilized for this purpose. In this paper however we will not dwell on the subject of utility estimations, rather we assume that the utilities of the respective assessments grade can be appreciated in a linear fashion. Therefore top level score of the hierarchy model can be obtained by $\sum \beta n u\left(H_{n}\right)$, $\mathrm{n}=1 \ldots \mathrm{N}$.

\section{First Case Study: Prioritization Of Maintenance-Related Waste}

The reduction and elimination of maintenance-related waste is receiving increasing attention because of the negative effect of such waste on production costs. The overall goal of this research is to identify and prioritize factors that can be considered maintenance-related waste within the automotive manufacturing industry [9].

\subsection{Identification of Waste}

To identify maintenance-related waste in the manufacturing industry, we held six workshops at five manufacturing companies. Brain writing and brainstorming were the main data collection tools. In total 465 maintenance-related wastes were discussed during the workshops. The classification into categories was performed by three researchers and through discussions, 16 final categories were decided upon. It was visible from the workshop analysis that the origin and cause of the maintenance-related waste could be linked to human factors. Therefore, in order for classification and model provision of maintenance-related waste linked to human activities, different literature in the area of human errors in maintenance field have been studied. the most efficient and relevant classification was related to a study about maintainer error by the Naval Safety Center's Human Factors Analysis and Classification System-Maintenance Extension (HFACS-ME) which was adapted for maintenance mishaps in aviation [10]. So, HFACS-ME is accepted as the basic framework and the 16 categories are incorporated into this model based on their similarity. The mentioned model is revised when no suitable category were found.

\subsection{Constructing Survey}

A survey was developed based on the identified maintenancerelated wastes on the lowest level of the hierarchy model. It contains 28 questions; because of having no informative knowledge about different type of the waste it is assumed that all the waste attributes have equal relative weight (importance). Five distinctive evaluation grades are used to assess each question: $\mathrm{H}=$ \{Very low, Low, Average, High, Very high\}. The respondents were asked to assess each waste by assigning their belief degree to these five grades. A belief degree represents the strength to which the grade is believed to be appropriate for describing the opinion on the criterion. For example subjective judgement of an expert for the first question about "how much "inadequate process" are responsible for waste was: (Very high $=0 \%$, High= $10 \%$, Average $=20 \%$, Low $=$ "no idea", Very low $=40 \%$ ).

\subsection{Data Analysis and Discussion}

The main purpose in prioritization the human factors responsible for maintenance-related waste was to identify strengths and weaknesses which could form a basis for subsequent detailed assessments and help create action plans to address the weaknesses. This means management teams can focus on different factors to reduce or eliminate waste based on their importance for creating waste. A Windows-based Intelligent Decision System (IDS) is applied to implement the ER approach. IDS is a general-purpose multiple criteria decision analysis tool; it provides graphical interfaces to build a decision. The group belief degrees entered for each evaluation grades and for 28 questions (which were designed based on the lowest level of MWC-HF model) into IDS. As result of IDS for rankings of maintenance-related waste at the lowest level shows, "inadequate resources" and "weather /indoor climate," with average scores of $54 \%$ and $22 \%$ respectively, are the highest and lowest average scores for creating maintenance-related waste; see Table 1. This prioritization methodology can be used as a tool to create awareness for managers seeking to reduce or eliminate maintenance-related waste.

Table 1. Ranking of the maintenance related waste created by human factors

\begin{tabular}{|c|c|c|}
\hline $\begin{array}{l}\text { Maintenance related waste based on human } \\
\text { factors }\end{array}$ & Score $(\%)$ & Rank \\
\hline Inadequate Resources & 54 & 1 \\
\hline Inadequate Supervision & 52 & 2 \\
\hline Mental State & 50 & 3 \\
\hline Poor EEM (Early Equipment Management) & 48 & 4 \\
\hline Inadequate Process & 47 & 5 \\
\hline Inadequate Documentation & 46 & 6 \\
\hline Poor Spare Part Handling & 45 & 7 \\
\hline Adaptability/ Flexibility & 43 & 8 \\
\hline Inadequate Design & 42 & 9 \\
\hline Inappropriate Operation & 42 & 10 \\
\hline Judgment / Decision Making & 40 & 11 \\
\hline Assertiveness & 38 & 12 \\
\hline Communication & 37 & 13 \\
\hline Training Preparation & 37 & 14 \\
\hline Physical State & 35 & 15 \\
\hline Unavailable/ Inappropriate & 35 & 16 \\
\hline Inadequate Customer Demand & 31 & 17 \\
\hline Certification Qualification & 30 & 18 \\
\hline Lack of Employee Engagement & 30 & 19 \\
\hline Inaccessible & 29 & 20 \\
\hline Supervisory Misconduct & 29 & 21 \\
\hline Limitation & 28 & 22 \\
\hline Infringement & 27 & 23 \\
\hline Uncorrected Problem & 27 & 24 \\
\hline Environmental Hazards & 26 & 25 \\
\hline Confining & 24 & 26 \\
\hline Error and Violation & 23 & 27 \\
\hline Weather/Indoor Climate & 22 & 28 \\
\hline
\end{tabular}




\section{Second Case Study: Developing Sustainable Product Development Strategy}

It has become increasingly important for producing companies to reduce their environmental impact. Companies are focusing more on preventing environmental issues by taking sustainability into the product development process, and not just reducing emissions from manufacturing the product [11].

Product development needs to be done with considering sustainability and without compromising future generation's ability to satisfy their needs. There are several strategies and methods developed to guide companies towards sustainability. The aim of this case study is to look at the possibility of having a new approach for sustainable design. So through a literature review six design strategies were taken into consideration in order to develop a new approach based on all advantages (sustainable factors) of the six approaches. Those six strategies are: ecodesign, green design, cradle-to-cradle, and design for environment, zero waste and life cycle approaches. Together with literature review an interviews were conducted with managers from companies working with product development in Sweden to identify as many sustainable factors as possible. For ranking and finding out about the most important factors the evidential reasoning (ER) approach is used. The reason for application of ER is the qualitative nature of the data (factors) which add more uncertainty. Based on the literature several advantages and disadvantages are defined, both in regard of the environment and in a business perspective [12].

\subsection{Result of Literature Review and Interview}

Results shows, Eco design is a tool with most advantages, and green design has most disadvantages. By looking at the advantages, patterns emerge in the different approaches. By grouping the 38 advantages below similar advantages are merged. The disadvantages that were found are fewer than the advantages, most likely because the research focus on the benefits of the strategies. Several of the advantages can be seen as factors of sustainable design and by defining them there is a possibility of finding which factors are important to a new approach to sustainable design. The factors that were found is presented, in Table 2 with the design strategies related to each factor. To support the literature review and find other factors than the ones conducted from the literature review, three semi structured interviews were conducted with managers from companies working with product development in Sweden. Factors that were drawn from the interviews are: material selection, reduce energy usage, reduce emissions, minimize use of toxic substances, increased competitiveness and economic benefits. Some of these factors correspond directly to factors drawn from the literature, but two factors are added: "material selection" and "reduce emissions".
Table 2 - Factors of sustainable design and the corresponding strategies

\begin{tabular}{ll}
\hline Factors & Design strategy \\
\hline Reduce energy usage & Eco-design \\
Reduce material usage & Eco-design, Life-cycle approaches \\
Reduce use of non-renewable & Green design \\
resources & \\
Reduce waste & Design for Environment \\
Eliminate waste & Cradle-to-cradle, Zero waste \\
Eliminate emission & Zero waste \\
Minimize use of toxic substances & Eco-design, Zero waste \\
Minimize waste & Green design \\
Recycle materials/component & Cradle-to-cradle, Design for \\
& environment, Zero waste, Life-cycle \\
& approaches, Eco-design \\
Reuse material/components & Zero waste, Life-cycle approaches, \\
Increase product functionality & Eco-design, Cradle-to-cradle \\
Increase product lifespan & Eco-design \\
Increase use of renewable energy & Eco-design \\
Increase use of renewable & Green design, Cradle-to-cradle \\
materials & Green design, Life-cycle approaches, \\
Increase use of biodegradable & Cradle-to-cradle \\
materials & Cradle-to-cradle \\
Closed loop material flow & Cradle-to-cradle \\
Holistic Approach & Life-cycle approaches, Cradle-to- \\
Social standards & cradle \\
Economic benefits & Green design, Cradle-to-cradle \\
Increased competitiveness & Eco-design, Cradle-to-cradle, Zero \\
& waste \\
& Eco-design \\
\hline & \\
&
\end{tabular}

\subsection{Constructing Survey}

Based on the 20 factors collected from the literature review and additional 2 factors collected from interviews a survey was designed. The survey was sent together with instructions to people working with product development. The respondents were asked to answer the importance of each factors in sustainable product development based on five grades of $\mathrm{H}=$ \{un-important, Not very important, Quite important, Important, Very important $\}$. They were given the opportunity to answer the questions by assigning their degree of belief, from 0 to $100 \%$, in different grades and for different answers. If they weren't sure of the importance of a factor, they could give the answer "don't know". The surveys were answered by 10 respondents with an average of 8 years of experience in product development.

\subsection{Data Analysis and Discussion}

The mean value for each grade and factor based on the results from the survey was calculated by adding up the respondents' degree of belief in each grade and entered into the IDS. The factors of sustainability are not arranged by hierarchy, it is assumed that all factors are top-level criteria.

The result of applying ER through IDS shows that all factors are important but the most important factors, with a percentage score of over $65 \%$, which is the mean value of all factors, are: "Minimize use of toxics substances" (82\%), "Increased competitiveness" (76\%), "Economic benefits" (75\%), "Reduce material usage" (74\%), "Material selection" (72\%), "Reduce emissions" (69\%), "Increase product functionality" (69\%), see Table 3.

By looking at the factors from Table 2 it is clear that most of the important factors are part of the eco-design strategy. Material selection" and "reducing emission" are factors that were obtained from interviews with companies. In other words all the important 
factors, apart from the one collected from interviews are a part of eco-design. So it means among all strategies eco-design is the most dominant strategy in term of environment.

\begin{tabular}{|c|c|c|}
\hline Factors & $\begin{array}{c}\text { Score } \\
(\%)\end{array}$ & Rank \\
\hline $\begin{array}{l}\text { Minimize use of toxic } \\
\text { substances }\end{array}$ & 82 & 1 \\
\hline Increased competitiveness & 76 & 2 \\
\hline Economic benefits & 75 & 3 \\
\hline Reduce material usage & 74 & 4 \\
\hline Material selection & 72 & 5 \\
\hline Reduce emissions & 69 & 6 \\
\hline Increase product functionality & 69 & 7 \\
\hline Reduce waste & 64 & 8 \\
\hline $\begin{array}{l}\text { Increase use of renewable } \\
\text { energy }\end{array}$ & 64 & 9 \\
\hline Social standards & 64 & 10 \\
\hline $\begin{array}{l}\text { Increase use of renewable } \\
\text { materials }\end{array}$ & 63 & 11 \\
\hline Holistic view & 62 & 12 \\
\hline $\begin{array}{l}\text { Recycling } \\
\text { components/materials } \\
\text { Reduce use of non-renewable } \\
\text { resources }\end{array}$ & $\begin{array}{l}61 \\
60\end{array}$ & 14 \\
\hline Minimize waste & 59 & 15 \\
\hline Reusing components/materials & 58 & 16 \\
\hline $\begin{array}{l}\text { Increase use of biodegradable } \\
\text { materials }\end{array}$ & 58 & 17 \\
\hline Increase product lifespan & 57 & 18 \\
\hline Eliminate emissions & 56 & 19 \\
\hline Reduce energy usage & 55 & 20 \\
\hline Circular material flow & 54 & 21 \\
\hline Eliminate waste & 53 & 22 \\
\hline
\end{tabular}

\section{Conclusion}

Many of the real life problems need making decision under uncertainty that is, choosing action among a set of actions considering different criteria based on often imperfect observations, with unknown outcomes. The Evidential Reasoning (ER) is one of the latest developments within MCDM literature and appears to be the best fit to handle uncertain information. ER can model multiple attribute decision problems which have both quantitative and qualitative attributes. In this paper ER is introduced and it is applied in two different case studies for prioritization and ranking of different factors. In the first case study it is applied to rank different maintenance related waste linked to human factors. The result showed, among all 28 factors identified in the workshop studies, "Inadequate Resources", "Inadequate Supervision", "Mental State of the workers" are the most important factors for creating waste by human in maintenance context at considered automotive manufacturing industry. Second case study look at the possibility of having a new approach for sustainable design. So through a literature review six design strategies were taken into consideration in order to develop a new approach based on all advantages (sustainable factors) of the six approaches. For ranking and finding out about the most important factors the evidential reasoning (ER) approach is used. After applying ER for the second case study the result showed among the sex sustainable design strategies most of the important factors were found in the eco-design strategy, however that strategy also contains factors that are not as important, and two of the important factors are not found in any strategy but in interviews. These factors represent the building blocks for a new approach. As a future research extension modelling of other type of uncertainty, such as interval uncertainties, uncertainties in other parameters of a decision problem such as criterion weights and belief degrees is recommended.

\section{Acknowledgment}

The research work is part of the initiative for Excellence in Production Research (XPRES) which is a cooperation between Mälardalen University, the Royal Institute of Technology, and Swerea. XPRES is one of two governmentally funded Swedish strategic initiatives for research excellence within Production Engineering.

\section{References}

[1] M. Zeleny, Multiple Criteria Decision Making. California: McGraw-Hill, 1982.

[2] L. H. Alencar, A. T. Almeida, D. C. A. Morais, “Multicriteria group decision model aggregating the preferences of decision-makers based on ELECTRE methods, Pesqui Oper, 30, 687-702, 2010.

[3] R. R Lekurwale, M. M Akarte, D. N. Raut, "Framework to evaluate manufacturing capability using analytical hierarchy process". Int J Adv Manuf Tech, 76(1), 565-576, 2015.

[4] T.L. Saaty, The Analytic Hierarchy Process. University of Pittsburgh. 1988.

[5] C.T. Chen, "A fuzzy approach to select the location of the distribution center". Fuzzy Set Syst, 118, 65-73, 2001.

[6] G.A Shafer,. Mathematical Theory of Evidence. Princeton University Press. 1976.

[7] J.B. Yang, B.G. Dale., C.H.R. Siow, "Self-assessment of excellence: an application of the evidential reasoning approach". Int J Prod Res, 39(16), 3789-3812, 2001.

[8] J. Pontus, L. Nordström, R. Lagerström, "Formalizing analysis of enterprise architecture". Lect Notes Bus Inf P, 35-44, 2007.

[9] F. Ahmadzadeh, M. Bengtsson, "Using evidential reasoning approach for prioritization of maintenance-related waste caused by human factors - a case study”, Int J Adv Manuf Tech,, https://doi.org/10.1007/s00170-016-9377-7, $1-15,2016$.

[10] J. Schmidt, D. Lawson, R. Figlock. Human factors analysis and classification system maintenance extension (HFACS-Me), review of select NTSB maintenance mishaps, an 2003. http://www.faa.gov/about/initiatives/intenance_hf/library/documents/ media/hfacs/ntsb hfacs-me updated study report.pdf

[11] G. Johansson, "Succes factors for integration of eco design in product development". Environmental Management and Health, 13(1), 98-107, 2002.

[12] F. Ahmadzadeh, K Jederströma M. Plahna, A. Olssona, I. Foyera "An investigation of the most important factors for sustainable product development using evidential reasoning", Numerical Algebra, Control and Optimization., In press. 